* Graduanda em Direito pelo Instituto Catuaí de Ensino Superior. Colaboradora do grupo de pesquisa Contratos em Biodireito e Democracia, Direitos Fundamentais e Acesso a Justiça. E-mail: gealaeneto@msn.com

** Mestre em Direito Negocial pela Universidade Estadual de Londrina. Especialista em Direito Civil e Processo Civil pela Universidade Estadual de Londrina. E-mail: loreannemcf@yahoo.com.br

\section{As Novas Formas de Entidades Familiares Advindas com a Constituição Federal de 1988 e a Reprodução Humana Assistida como Instrumento Facilitador para a Formação das Famílias Homoafetivas}

\author{
New Forms of Entities Arising Family in \\ THE Federal Constitution OF 1988 AND \\ Human Assisted Reproduction as a tool \\ FOR THE Formation OF HoMOSEXUAL FAMILIES
}

\author{
Geala Geslaine Ferrari * \\ Loreanne Manuella de Castro França **
}

Resumo: Com o advento da Constituição Federal de 1988 houve uma ampliação no conceito de família, devido ao reconhecimento de novas entidades familiares além daquela oriunda do matrimônio. Assim, a família passou a ser definida como uma instituição pluralista, sempre entrelaçada aos valores da dignidade, igualdade e solidariedade, tendo como fim o afeto, independentemente de sua escolha sexual. Após a decisão do Supremo Tribunal Federal que equiparou a união estável homoafetiva à heterossexual, novos direitos foram assegurados aos homossexuais. Desde então, com base no planejamento familiar e princípio constitucional da paternidade responsável, os casais homossexuais estão buscando, através das técnicas de reprodução humana assistida, a possibilidade de ampliação familiar. Nesses casos, a técnica a ser aplicada deverá ser sempre a fertilização in vitro (reprodução humana assistida heteróloga), tendo em vista a necessidade da presença de um terceiro, estranho à relação, o doador: em casais femininos há a doação do esperma pelo terceiro, a cessão do óvulo por uma das parceiras e a cessão do útero por outra; em casais masculinos, há a doação do óvulo por uma terceira, a cessão do esperma por um dos parceiros e a realização da gestação por substituição, comumente denominada "barriga de aluguel", na qual mais uma pessoa fora da relação homoafetiva oferece seu útero para o desenvolvimento da gravidez, devendo ser observados os requisitos estabelecidos na Resolução no 1957/2010 do Conselho Federal de Medicina. A realização desse projeto de família homoparental gera direitos e deveres ao casal homoafetivo, oriundos da obrigação de exercerem uma paternidade responsável e do exercício do poder 
familiar. Nesse meio, muitas conquistas já foram alcançadas pelos casais homossexuais, especialmente a possibilidade de registro duplo na Certidão de Nascimento dos filhos - pai e pai, mãe e mãe. Porém, ainda restam controvérsias e indefinições em razão da falta de legislação específica sobre tais técnicas de fecundação artificial, cabendo, então, ao Poder Judiciário dirimir eventuais conflitos, com base na análise dos casos concretos e aplicação dos princípios fundamentais do Direito de Família.

Palavras-chave: Família homoafetiva. Ampliação familiar. Reprodução humana assistida.

Abstract: With the advent of the Federal Constitution of 1988 there was an expansion in the concept of family, due to the recognition of new family entities beyond that coming from the marriage. So the family came to be defined as a pluralistic institution, always intertwined with the values of dignity, equality and solidarity, in order to affection, regardless of their sexual choice. After the Supreme Court decision that equated the homoafective relationship as the heterosexual relationship, new rights were secured for homosexuals. Since then, based on the constitutional principles of family planning and responsible parenthood, homosexual couples are seeking, through the techniques of assisted human reproduction, the possibility of expanding family. In such cases the technique to be applied must always be in vitro fertilization (heterologous human assisted reproduction), in view of the necessity of the presence of an odd person to the relationship, the donor: in female pairs, the sperm is donated by the third, the transfer of the egg by one of the partners and the assignment of the uterus by another; in men couples, the egg is donated by the third, the transfer of sperm by one partner and the achievement of pregnancy is by substitution, commonly called "surrogacy", in which another person outside the homoafective relationship offers her uterus for pregnancy development and should be complied with the requirements set forth in Resolution No. 1957/2010 of the Federal Council of Medicine. The realization of this project of homoparenthood family generates rights and duties for the couple, from the obligation to exercise responsible parenthood and the exercise of family power. In this environment, many achievements have been reached by homosexual couples, especially the possibility of double registration in the birth certificate of the children - father and father, mother and mother. However, there are still controversies and uncertainties due to the lack of specific legislation on such techniques of artificial fertilization, fitting, then, to the Judiciary resolve any conflicts, based on analysis of cases and applying the fundamental principles of family law. 


\section{INTRODUÇÃO}

Desde a promulgação da Constituição Federal de 1988, significativas mudanças vêm ocorrendo no conceito de família, devido à elevação ao status de entidade familiar outras formas de família não advindas do matrimônio. Por esta razão, o Direito de Família tem se tornado cada vem mais metamórfico, considerando a formação da família pelos laços da afetividade, solidariedade e ajuda mútua.

A decisão do Supremo Tribunal Federal no julgamento da ADI n ${ }^{\circ} 4277$ e $\mathrm{ADPF}^{\mathrm{o}} 132$ - que determinou interpretação conforme a Constituição do artigo 1723 do Código Civil - deixou clara a não discriminação da relação homoafetiva e sua equiparação à união estável heterossexual. Sendo assim, a eles foram equiparados direitos e obrigações pertencentes ao instituto da união estável, como a conversão em casamento, bem como a possibilidade de participação em técnicas de reprodução humana assistida, a fim de ampliar sua família.

No presente trabalho, pretende-se traçar uma linha conceitual da família antes do advento da Constituição Federal de 1988, após a vigência da atual Carta Magna, e na contemporaneidade, enfatizando, de forma especial, a formação da família homoafetiva e seus conceitos doutrinários e jurisprudenciais.

Ademais, será analisada a possibilidade desses casais realizarem o seu projeto de família por meio da submissão a técnica de reprodução humana assistida, demonstrando os efeitos jurídicos criados no mundo fático a partir da realização de tais procedimentos e do nascimento das crianças.

Por se tratar de um tema atual, que envolve profunda pesquisa e pouca legislação, utiliza-se do método teórico para dar fundamento às posições adotadas neste ensaio.

Entendendo ser um tema de extrema importância ao mundo jurídico e à sociedade como um todo cumpre identificar os resultados para os quais tal pesquisa levará: defender a possibilidade da formação da família homoafetiva através das técnicas de reprodução humana assistida ou, sendo esta impossível, mediante a adoção.

\section{O CONCEITO MODERNO DE FAMÍLIA E AS MUDANÇAS ADVINDAS COM A CONSTITUIÇÃO FEDERAL DE 1988}

No direito pátrio até a Constituição Federal de 1988 e Código Civil de 2002, o conceito de família albergava definições pertencentes ao Direito 
Romano. Na Roma antiga, a família era patriarcal e estava sujeita a autoridade do patria potestas - ascendente comum mais velho -, que tinha o poder soberano de um chefe sob todos os descendentes aliena iures, os não emancipados, sua esposa, as esposas de seus descendentes e escravos.

Sobre a família romana, Caio Mário da Silva Pereira (2007, p.23) ensina que:

Em Roma a família era organizada sobre o princípio da autoridade, exercida sobre o pater família, que abrangia quantos a ele estavam submetidos. $\mathrm{O}$ pater era ao mesmo tempo, chefe político, sacerdote e juiz. Comandava, oficiava o culto aos deuses domésticos e distribuía justiça.

Para Luiz Edson Fachin (2003, p.57), no Direito Romano as relações familiares são reconstruídas aos moldes da conformação social, onde casal, filhos, escravos e servos estavam sob a autoridade do pater familias.

$\mathrm{O}$ antigo Código Civil possuía seu eixo central voltado à proteção da propriedade, o que influenciava diretamente no Direito de Família. Porém, com o advento da Constituição

Federal de 1988 e seu linha voltada à dignidade da pessoa humana, a base do Direito de Família foi reestruturada, com o reconhecimento de novas entidades familiares e o fim da discriminação no seio da família.

Atualmente, diz-se que a família recebe, por parte de seus membros, os mais variados conceitos, pois representa uma associação de pensamentos antropológico, biológico, psicológico e até mesmo religioso, ao ser chamada, por Giselda Hironaka (2000, p. 27), "como um elemento espiritual”.

Juridicamente, é essencial demonstrar que no Código Civil anterior, por se tratar de um sistema paternalista, matrimonializado e hierarquizado, o conceito de família encontravase permeado de resquícios do Direito Romano, principalmente no que diz respeito à autoridade e paternidade. Todavia, após a Carta Constitucional de 1988, muitas mudanças se consolidaram no âmbito do direito familiar, trazendo igualdade e abertura às novas formas familiares.

O artigo 226, caput, da Constituição Federal traz a família como base da sociedade, merecedora de proteção do Estado. Em seu $\S 3^{\circ}$, demonstra o status de família atribuído à entidade familiar não matrimonializada, com o reconhecimento da união estável. Já no $\S 4^{\circ}$ possibilita a formação de família monoparental, sendo aquela formada por um dos pais e filhos, podendo ser 
mãe e filhos ou pai e filhos. Por fim, no $\S 5^{\circ}$ observa-se que o legislador, mais uma vez, declinou sua atenção a um dos princípios basilares de toda a Carta Maior, qual seja, o princípio da igualdade, determinando a proibição à diferenciação entre homem e mulher. Referida interdição veio por fim a toda e qualquer discriminação que houvesse entre filhos legítimos e ilegítimos e também entre homem e mulher, no âmbito da autoridade familiar.

Segundo Maria Berenice Dias, a família atual, por dispor de várias formatações, precisa ter um espectro cada vez mais abrangente:

Mais do que uma definição, acaba sendo feita a enumeração dos vários institutos que regulam não só as relações entre pais e filhos, mas também entre cônjuges e conviventes, ou seja, a relação das pessoas ligadas por um vínculo de consanguinidade, afinidade ou afetividade (DIAS, 2011, p. $33)$.

De acordo com Paulo Nader (2006, p.3), família pode ser compreendida como "uma instituição social, composta por mais de uma pessoa física, que se irmanam no propósito de desenvolver, entre si, a solidariedade nos planos assistenciais e da convivência ou simplesmente descendem uma da outra de um tronco comum".

Para Luiz Edson Fachin (2003, p.9) o conceito de família do Código Civil de 2002 nasceu excludente, no que diz respeito ao debate mais amplo sobre a união estável, à família fraterna, aquela formada entre irmãos e a filiação socioafetiva.

Constata-se, então, que a doutrina moderna do direito familiar defende uma visão pluralista do conceito de entidade familiar, na qual podem ser abrigados os mais diversos arranjos familiares, buscando-se sempre identificar o elemento que permite encaixar no conceito de família todos os relacionamentos que tem origem em um elo de afetividade (DIAS, 2011, p.36). Para Giselle Groeninga (2003, p.126), esse é o divisor entre o direito obrigacional e o familiar: os negócios têm por substrato exclusivo a vontade, enquanto o traço diferenciador do Direito da Família é o afeto.

A união estável é um exemplo de uma sociedade de fato que se transformou em sociedade de afeto, pois não se pode acreditar que o motivo que leva duas pessoas a manter um relacionamento seja o exercício de uma atividade econômica e a partilha dos resultados, mas sim a constituição de um lar. 
Mesmo que os direitos dos companheiros sejam diferentes dos pertencentes ao casamento, o fato da união estável não ser mais considerada apenas uma sociedade de fato faz com que suas lides sejam de competência da vara da família e não mais da seara obrigacional.

Para ser considerada união estável, conforme o artigo 226 , $\$ 3^{\circ}$, da Constituição Federal, artigo 1723 do Código Civil e Lei nº 9278/96, alguns requisitos devem ser observados: relação entre homem e mulher, convivência pública, contínua e duradoura, objetivo de constituir família. No entanto, após o julgamento da ADI no 4.277 e ADPF no 132, o Supremo Tribunal Federal passou a considerar união estável a relação entre pessoas, de convivência pública, contínua e duradoura com o objetivo de constituição de família ${ }^{1}$. Em consequência, como se pode observar, deixou-se de lado o requisito anteriormente exigido, quanto à diferenciação de sexo na constituição da união estável, colocando-se em mesmo nível a união estável homossexual e a união estável heterossexual.

Referida equiparação trouxe reconhecimento à família homoafetiva que vivia à margem da sociedade, buscando no Judiciário uma solução para seus problemas, conseguindo apenas, na maioria das vezes, uma sentença que declarava ser sua relação familiar uma sociedade de fato. Ainda que houvesse uma minoria na jurisprudência que declarasse seus direitos, por exemplo, o atuante Tribunal de Justiça do Rio Grande do Sul, um dos primeiros a dar direitos concretos a casais homoafetivos, tais anseios permaneciam no campo dos direitos obrigacionais.

Segundo Orlando Gomes (1999, p.391), as famílias homoafetivas, como sociedades de fato, eram consideradas como pessoas que reuniam esforços ou capitais para empreendimento comum de finalidade econômica mediante contrato.

E, antes de se tentar enquadrar a família dentro dos moldes da lei ou dos ditos sociais, morais ou pessoais, interessante recordar os ensinamentos de Guilherme Nogueira Calmon (2001, p.23) ao dizer que a família, antes de mais nada, é uma realidade, um fato natural, uma criação da natureza, e não um resultado da criação do homem.

\footnotetext{
${ }^{1}$ Em pedido subsidiário, a Procuradoria-Geral da República requer o conhecimento da presente ADPF como Ação Direita de Inconstitucionalidade, com pedido de interpretação conforme do art. 1.723 do Código Civil. Assim sendo, e com base na jurisprudência desta Corte (ADPF-QO n 72, Rel. Min. Ellen Gracie, DJ 2.12.2005), conheço da ação como ação direta de inconstitucionalidade, cujo objeto é o art. 1.723 do Código Civil." (ADPF 178, Min. Gilmar Mendes, no exercício da Presidência). Tal transcrição consta no voto do Min. Ayres Britto no julgamento da ADPF 132 e ADI 4277, p. 5.
} 
Sobre as mudanças ocorridas no que tange às famílias homoafetivas, Luis Edson Fachin (2003, p.35) aduz que "as transformações no contexto dos casais homoafetivos decorrem, dentre outras razões, de alterações das razões de ser das relações familiares, que passam agora a dar origem a um berço de afeto, solidariedade e mútua constituição de uma história em comum".

Ressalta-se que antes mesmo das decisões da Corte Suprema, a Jurisprudência já vinha desenhando esse caminho que culminou na equiparação da união estável entre casais heterossexuais e homossexuais: em 1998, o Ministro Ruy Rosado de Aguiar, do Superior Tribunal de Justiça, no julgamento do REsp 148.897/MG, determinava direitos que esses ainda não possuíam ao dizer que as "relações entre casais homossexuais constituem sociedade de fato e ensejam partilha do bem comum"; em 1991, o Ministro Sálvio de Figueiredo Teixeira vai afirmar que a Justiça não pode seguir dando respostas mortas a perguntas vivas, ignorando a realidade social subjacente, encastelando-se no formalismo, para deixar de dizer o direito.

A família contemporânea é chamada por alguns doutrinadores como eudemonista, pois os membros pertencentes a ela são ligados pelo afeto e buscam a felicidade.

Sob as relações de afeto, de solidariedade e de cooperação, proclama-se, com mais assento, a concepção eudemonista da família: não é mais o indivíduo que existe para a família e para o casamento, mas a família e o casamento existem para o seu desenvolvimento pessoal, em busca de sua aspiração à felicidade (FACHIN, 2003, p.56).

Tecidas as devidas considerações sobre a evolução no conceito de entidade familiar, passa-se a análise das técnicas de reprodução humana assistida e do planejamento familiar, chave para que os casais homossexuais, com sua união estável reconhecida, possam obter a ampliação familiar almejada.

\section{O BIODIREITO, A REPRODUÇÃO HUMANA ASSITIDA E O PLANEJAMENTO FAMILIAR}

Para entender o alcance do Biodireito é necessário que antes se entenda o conceito de Bioética. 
Maria Helena Diniz (2002, p.10) define a Bioética como uma resposta da ética às novas situações oriundas da ciência no âmbito da saúde, bem como um conjunto de reflexões filosóficas e morais sobre a vida em geral e sobre as práticas médicas em particular. Para Fachin (2003, p.245), a Bioética tem como objetivo apontar diretivas a partir de um patrimônio comum de valores.

Temporalmente, o termo Bioética só veio a tona na década de 70, no momento pós Segunda Guerra Mundial, em decorrência das atrocidades genéticas cometidas contra o ser humano, quando a comunidade internacional, através do Tribunal de Nuremberg condenou solenemente as experiências desumanas, levando ao surgimento de regras para experiências com seres humanos. Para Regina Fiúza Sauwen e Severo Hryniewicz (2000, p.45), este código constituiu o primeiro indicador de cunho universal da necessidade de aliar a pesquisa cientifica ao respeito pelo ser humano, podendo ser considerado o documento mater da Bioética.

Segundo Mário López (1997, p.215), Bioética é o estudo sistemático da conduta humana nas áreas das ciências da vida e dos cuidados da saúde, à medida que tal conduta é examinada à luz dos valores e princípios morais. Em seguida, define os três princípios sobre os quais se assenta: a beneficência, pelo qual busca-se a promoção e bem-estar dos outros, a autonomia, que atribui ao médico o dever de respeitar a vontade, a crença e os valores morais do paciente, e a justiça, que impõe a responsabilidade do médico em relação a suas condutas, principalmente em temas como transplantes, reprodução humana assistida, dentre outros.

O Biodireito é definido por Heloísa Helena Gomes Barbosa (2010) como "o ramo do Direito que trata da teoria, da legislação e da jurisprudência relativas às normas reguladoras da conduta humana em face dos avanços da Biologia, da Biotecnologia e da Medicina".

Portanto, o Biodireito pode ser compreendido como uma ciência jurídica voltada para a positivação de normas que buscam regular as experiências científicas aplicadas ao homem, impondo sanção ao desrespeito a pessoa humana, objeto de tais pesquisas.

Ivan de Oliveira Silva (2008, p.75) aduz que o Biodireito se ocupa com o tratamento jurídico relacionado à vida humana, como por exemplo, com as novas técnicas de reprodução humana assistida e suas consequências 
na rotina forense. Em decorrência disso, entende-se que a Bioética e o Biodireito possuem como objetivo impor limitações à biociência e as experiências científicas que possam afetar a saúde do ser humano, com o fim de garantir o respeito à dignidade humana e à vida em todas as suas dimensões.

Por fim vale expressar que, segundo Norberto Bobbio (1992, p.32), tais temas remetem-se aos direitos de quarta dimensão, os quais têm por fim normatizar os efeitos da revolução biotecnológica.

Analisados os conceitos de Bioética e Biodireito, dá-se continuidade com o estudo sobre a reprodução humana assistida, forma de ampliação familiar muito utilizada nos dias de hoje, não só pelos casais heterossexuais, mas também por homossexuais.

Em apertada síntese, a reprodução humana assistida pode ser entendida como um conjunto de técnicas que favorecem a fecundação humana a partir da manipulação de gametas e embriões, objetivando principalmente combater a infertilidade e proporcionando assim o nascimento de uma nova vida humana. Tal procedimento pode-se dar através da inseminação artificial, da fecundação artificial in vitro (FIV), da transferência intratubária de gametas (GIFT), da transferência de zigoto nas trompas de falópio (ZIFT) e da transferência em estágio de pró-núcleo (PROST). Também pode ser classificada como homóloga e heteróloga, sendo a primeira aquela que se dá quando não há interferência de material genético de terceiro na formação do embrião, e a segunda na qual há doação do material genético de terceiro.

Cristiane Beuren Vasconcelos (2006, p.142) define que "atrelado a palavra reprodução humana encontra-se intrínseco um significado de caráter subjetivo, a possibilidade de o ser humano dar continuidade à espécie, deixando um legado de sua existência neste mundo, e isto está ligado a sua dignidade".

A reprodução assistida possui uma grande importância, pois garante àqueles que por alguma razão são estéreis ou àqueles que possuem relações homoafetivas, o direito de procriar e constituir uma família junto de seus descendentes.

A Resolução no 1358/1992 do Conselho Federal de Medicina, vigente até o ano de 2010, trazia as limitações às técnicas de reprodução humana assistida, indicando o sujeito capaz de ser submetido a tal tratamento e estabelecendo a obrigatoriedade da aprovação do cônjuge ou companheiro, 
na hipótese da interessada em se submeter às técnicas de reprodução humana assistida ser casada ou em união estável. Todavia, a Resolução $n^{\circ}$ 1957/2010 veio modificar a Resolução nº 1358/1992, largando os sujeitos a quem tal instrumento reprodutivo alcança, passando a estabelecer todas as pessoas capazes, independentemente de sexo e estado civil.

O direito à saúde é um direito constitucionalmente adquirido, que se faz presente no rol dos direitos sociais definidos no artigo $6^{\circ}$ e no artigo 199 da Constituição Federal, cujo $\S 4^{\circ}$ estatui que "A lei disporá sobre as condições e os requisitos que facilitem a remoção de órgãos, tecidos e substâncias humanas para fins de transplante, pesquisa e tratamento, bem como a coleta, processamento e transfusão de sangue e seus derivados, sendo vedado todo tipo de comercialização", podendo-se inserir neste dispositivo legal, ainda que implicitamente, a reprodução humana assistida. Destarte, é direito de toda pessoa capaz, que possua dificuldade de procriação por infertilidade ou impossibilidade pela falta de relação com diversidade de sexo, buscar auxílio do Estado pleiteando tratamento eficaz, neste caso técnicas reprodutivas artificiais.

$\mathrm{O}$ artigo 226 da nossa Carta Magna, em seu $\S 7^{\circ}$, define que, fundado na dignidade humana e na paternidade responsável, o planejamento familiar é livre decisão do casal, competindo ao Estado propiciar recurso para o exercício desse direito.

O planejamento familiar está disposto na Lei $n^{\circ}$ 9263/96, cujo artigo $2^{\circ}$ o conceitua como "como o conjunto de ações de regulação da fecundidade que garanta direitos iguais de constituição, limitação ou aumento da prole pela mulher, pelo homem ou pelo casal".

A ilustre doutrinadora Maria Helena Diniz (2002, p.133) ensina que o planejamento familiar está vinculado à liberdade de decisão de cada casal que passa a ser responsável não só pelo número de filhos, como também por seu desenvolvimento físico, moral, educação, saúde e proteção.

Salienta-se, outrossim, que os direitos reprodutivos e sexuais fizeram parte da Conferência Internacional de Beijing, em 1995, na qual foram firmados como direitos básicos de todos os casais e indivíduos a decisão livre e responsável do número de filhos, espaçamento dos nascimentos e o intervalo entre eles, como a informação dos meios para tanto e o direito de alcançar o nível mais alto de saúde sexual e reprodutiva. 
A decisão da Suprema Corte Nacional propiciou a extensão dos direitos relativos aos casais em união estável aos casais do mesmo sexo, motivo pelo qual a Resolução do Conselho Federal de Medicina que regulamenta as técnicas reprodutivas alargou os sujeitos que podem fazer tais procedimentos. Resta demonstrada, então, a possibilidade da formação das famílias homoafetivas, que não mais estão escondidas por de trás da névoa do preconceito, sendo, nos dias de hoje, uma entidade familiar juridicamente protegida pelo Estado, tendo como método facilitador a reprodução humana assistida

Passa-se, neste estágio do trabalho, a tratar sobre a concepção das famílias homoparentais em si, geradas através de meios de fecundação artificiais, formadas por casais homossexuais femininos ou masculinos.

\section{AS FAMÍLIAS HOMOAFETIVAS FRUTO DA REPRODUÇÃO HUMANA ASSISTIDA E SEUS REFLEXOS NO DIREITO PÁTRIO}

A família moderna pode ser conceituada como uma instituição plural que tem como fim o afeto, o companheirismo e a solidariedade, independente de sua orientação sexual.

Dentro dessa diversidade de entidades familiares insere-se a família homoafetiva, formada por casais do mesmo sexo, podendo ser femininos ou masculinos, que estão sob o regime de união estável, possuindo características como: uma relação entre pessoas, convivência duradoura e objetivo de constituição de família.

Consoante já explicitado, a Constituição Federal de 1988 foi um divisor de águas para o direito familiar, pois a partir de sua promulgação passou-se a se reconhecer juridicamente formas familiares outrora desprezadas pelo sistema legal. Contudo, nela não se encontra expressamente a garantia dos direitos das famílias homoparentais.

Sobre o tema, Maria Berenice Dias assevera que:

Por absoluto preconceito, a Constituição Federal emprestou de modo expresso juridicidade somente às uniões estáveis entre um homem e uma mulher, ainda que em nada se diferencie a convivência homossexual da união estável. A nenhuma espécie de vínculo que tenha por base o afeto se pode deixar de conferir status de família, merecedora da proteção do Estado, pois a Constituição Federal consagra, em norma pétrea, o respeito à dignidade da pessoa humana. (DIAS, 2011, p.47). 
As relações homoafetivas, vistas anteriormente como sociedade de fato, eram assunto da seara obrigacional, suas lides eram dirimidas de forma que cada parceiro era tratado como sócio, e era assegurado a estes a divisão dos bens amealhados durante o período de convívio de forma proporcional à efetiva participação na sua aquisição.

Porém, há um considerável lapso temporal a jurisprudência já vinha traçando uma linha de entendimento jurídico no sentido de garantir maiores direitos aos casais homoafetivos.

No Agravo de Instrumento ${ }^{\circ}$ 599075496, de 17 de junho de 1999, da $8^{\text {a }}$ Câmara Cível do Tribunal de Justiça do Rio Grande do Sul, deu-se a primeira concessão de direitos aos casais homossexuais possibilitando que suas lides fossem conhecidas em Vara da Família, reconhecendo como entidade familiar o relacionamento de pessoas do mesmo sexo e deferindo o direito de herança pelo parceiro.

A própria Lei $n^{\circ} 11.340 / 2006$ - Lei Maria da Penha, em seu artigo $5^{\circ}$ (BRASIL, 2006), determina que seja configurada como violência doméstica e familiar contra a mulher qualquer ação ou omissão baseada no gênero que lhe cause morte, lesão, sofrimento físico, sexual ou psicológico e dano moral ou patrimonial. Em seguida, no seu parágrafo único assegura que as relações pessoais enunciadas independem de orientação sexual, o que significa que protege as mulheres que sofrem violência doméstica não só de seus maridos ou companheiros, mas também de suas parceiras ou companheiras, reconhecendo assim a existência da relação homoafetiva.

A luta da doutrina e jurisprudência era incessante em se promover a equiparação entre união estável heterossexual e homossexual, sendo Maria Berenice Dias umas das primeiras a enfrentar o tema.

Consoante palavras de Andréa Rodrigues Amin:

Se duas pessoas passam a ter vida em comum, cumprindo os deveres de assistência mútua, em um verdadeiro convívio estável caracterizado pelo amor e pelo respeito mútuo, com o objetivo de construir um lar, tal vínculo, independentemente do sexo de seus participantes, geram direitos e obrigações que não podem ficar à margem da lei. E as leis reguladoras do relacionamento entre homem e mulher podem e devem ser aplicadas as relações homossexuais. (AMIN, 2002, p.434). 
Em 2006, por decisão do Tribunal de Justiça do Rio Grande do Sul, foi reconhecido o direito da parceira adotar os filhos de sua companheira, uma vez que essa adoção tinha sido planejada para se dar em conjunto. Tal decisão foi confirmada pelo Superior Tribunal de Justiça que declarou ser a divergência de sexo indiferente para a configuração de uma família.

Finalmente, em 2010 essa problemática toda foi dirimida com o acórdão do julgamento do Supremo Tribunal Federal sobre a ADI n ${ }^{\circ} 4277 \mathrm{e}$ ADPF $n^{\circ} 132$, que determinou uma interpretação conforme a Constituição do artigo 1723 do Código Civil, salientando também que o não reconhecimento da união entre pessoas do mesmo sexo contrariava preceitos fundamentais como igualdade, liberdade e dignidade humana. Sendo assim, as uniões homoafetivas passaram a ser reconhecidas como entidades familiares, com a incidência da legislação relativa à união estável, assegurando a partilha de bens, os direitos sucessórios e o direito real de habitação.

Acerca da decisão prolatada pelo Supremo Tribunal Federal, discorre Maria Berenice Dias:

A decisão histórica, proferida por unanimidade, dispõe de eficácia contra todos e efeito vinculante, relativamente aos demais órgãos do Poder Judiciário e à administração pública direta e indireta, nas esferas federal, estadual e municipal. A desobediência dá ensejo a pedido de reclamação diretamente ao STF. (DIAS, 2011, p.207).

O avanço no campo da biotecnologia produziu reflexos nas estruturas familiares, fazendo surgir novas formas de filiação, originadas a partir da utilização de técnicas de reprodução humana assistida, as quais são conceituadas, por Jussara Meirelles (2002, p.391-402), como técnicas de interferência no processo natural de procriação.

Em se tratando de casal homoafetivo feminino o óvulo de uma das parceiras é extraído e fertilizado in vitro e, após, implantado no útero da outra que gestará a criança. Ao se deparar com esse caso, o primeiro questionamento que surgiu foi com relação à maternidade da criança, pois, em sendo casal homoafetivo feminino, a criança teria duas mães.

Enfrentando o tema, o juiz da $6^{\text {a }}$ Vara de Família de Santo Amaro/SP, Fábio Eduardo Basso, concedeu, pela primeira vez, o direito de se ter na certidão de nascimento o nome de duas mães, a dupla maternidade: 
No caso em tela, as requerentes vivem juntas e resolveram ter filhos, valeu-se de um método avançado da medicina. As crianças são frutos da junção dos óvulos de uma com os espermatozóides de um doador. Possuem as afortunadas crianças DUAS MÃES, por isso julgo procedente o pedido de reconhecimento de dupla maternidade.

Com essa decisão, sobrevieram outras que também declararam a dupla maternidade, como em ação que tramitou perante a $2^{\mathrm{a}}$ Vara de Registros Públicos de São Paulo, relativo a gêmeos concebidos por meio de reprodução assistida, que passaram a ter em sua certidão de nascimento o nome de duas mães.

Também, a Justiça de Jacaré́/SP, no dia 28 de Maio de 2012, acolheu o pedido de duas mães para que seus nomes fossem constados na certidão de nascimento de seu filho concebido pelo método de fecundação artificial.

Salienta-se que, nos casos acima descritos, o pleito foi deferido com fundamento nos princípios da liberdade, igualdade, dignidade da pessoa humana e principalmente no direito que o casal tem de fazer seu planejamento familiar, cumprindo assim com o dever da paternidade responsável.

$\mathrm{Na}$ hipótese de casal homoafetivo masculino a situação é diversa, considerando a necessidade de outras pessoas (terceiros) alheios à relação: há a doação do óvulo por uma terceira, a cessão do esperma por um dos parceiros e a realização da gestação por substituição, comumente denominada "barriga de aluguel".

Porém, diferentemente de outros países, no Brasil, para a utilização do método da gestação por substituição, ou "barriga de aluguel", alguns requisitos, previstos na Resolução no 1957/2010 do Conselho Federal de Medicina, devem ser observados:

\section{VII - SOBRE A GESTAÇÃO DE SUBSTITUIÇÃO (DOAÇÃO TEMPORÁRIA DOÚTERO)}

As clínicas, centros ou serviços de reprodução humana podem usar técnicas de RA para criarem a situação identificada como gestação de substituição, desde que exista um problema médico que impeça ou contraindique a gestação na doadora genética. 1 - As doadoras temporárias do útero devem pertencer à família da doadora genética, num parentesco até o segundo grau, sendo os demais casos sujeitos à autorização do Conselho Regional de Medicina. 
2 - A doação temporária do útero não poderá ter caráter lucrativo ou comercial.

Vislumbra-se, portanto, que para ser possível e legal a gestação por substituição, é necessário que a doadora do útero seja da família da doadora genética, no máximo até o segundo grau, que a impossibilidade de gestar o bebê seja comprovada, podendo esta se dar quando se tratar de casal homossexual masculino, bem como que mãe ou pai biológicos sejam capazes. Ressalta-se que, em hipótese nenhuma poderá haver pagamento pelo útero concedido para a gestação, conforme estipula o artigo $199, \S 4^{\circ}$, da Constituição Federal:

$\S 4^{\circ}$ A lei disporá sobre as condições e os requisitos que facilitem a remoção de órgãos, tecidos e substâncias humanas para fins de transplante, pesquisa e tratamento, bem como a coleta, processamento e transfusão de sangue e seus derivados, sendo vedado todo tipo de comercialização. (BRASIL, 1988).

Para Eduardo de Oliveira Leite (1995, p. 187), o termo "barriga de aluguel" confunde-se com gestação por substituição, uma prática de acordo com a qual uma mulher carrega uma criança para outra mulher com a intenção de lhe entregar esta após o nascimento.

Já no posicionamento de João Baptista Villela (1999), a gestação por substituição é um negócio jurídico de comportamento, compreendendo para a mãe de aluguel obrigações de fazer e não fazer, culminando com a obrigação de dar, consistente na entrega do filho.

Por sua vez, Luiz Edson Fachin (2003, p.256) aduz que a atitude da mãe de aluguel, ou seja, aquela que cede seu útero, pode ser explicada pelo parentesco e pela benemerência, gratuidade e impossibilidade da reprodução pelas vias normais, equilibrando o regime de doação gratuita e temporária do útero.

Quanto à filiação da criança nascida por meio de reprodução humana assistida de casal homoafetivo masculino com gestação de substituição, observa-se que decisões já foram prolatadas determinando o registro duplo pai e pai. A primeira delas data de 07 de Março de 2012, na $1^{\text {a }}$ Vara de Família de Recife/PE, pelo juiz Glicério Bezerra e Silva, que proferiu sentença favorável ao registro de uma filha com dupla paternidade gerada por gestação de substituição por uma prima de um dos pais. 
Diante do exposto, constata-se que a reprodução humana assistida pode ser considerada um meio eficaz para a formação da família homoafetiva, que já possui diversos direitos reconhecidos, entre eles o de recorrer a essa forma de gestação a fim de ampliar sua estrutura familiar.

\section{CONCLUSÃO}

A sistematização dada a esse trabalho procurou buscar conceitos doutrinários sobre a família do passado e do presente, principalmente abordando os conceitos atuais sobre as relações familiares entre pessoas do mesmo sexo.

Por meio da pesquisa realizada, chegou-se a conclusão que família é uma instituição plural, identificada por muitos doutrinadores como eudemonista e socioafetiva, ligada pelos laços da afetividade, sem abrigar nenhuma forma de preconceito.

Verificou-se ainda que por mais que militassem sob a névoa do preconceito os casais homoafetivos há muito tem travado uma luta incessante pelo reconhecimento de seus direitos, o que culminou com a sua transformação de sociedade de fato pertencente ao campo do Direito Civil à entidade familiar incluída na esfera do Direito de Família.

Diante do reconhecimento, pelo Supremo Tribunal Federal, de efeitos jurídicos relativos à união estável homoafetiva, o uso do procedimento de reprodução humana assistida para ampliação dessa espécie de entidade familiar tornou-se possível, consubstanciado, também, na Resolução $n^{\circ}$ 1957/ 2010 do Conselho Federal de Medicina.

A reprodução assistida em casais do mesmo sexo será sempre do tipo heteróloga e sempre haverá um terceiro estranho a relação afetiva, o doador de parte do material genético: se casal homoafetivo feminino, uma das parceiras poderá doar o óvulo e a outra deverá ceder seu útero para a gestação; na hipótese de casal homoafetivo masculino, há a doação do óvulo por uma terceira, a cessão do esperma por um dos parceiros e a realização da gestação por substituição, observados os ditames da Resolução n ${ }^{0}$ 1957/ 2010 do Conselho Federal de Medicina e o artigo 199 da Constituição Federal.

Esse procedimento de reprodução humana assistida por casais homoafetivos e o nascimento de uma criança nesse seio familiar, traz 
consequências para todos, inclusive para o Estado, que tem o dever de regular legalmente essa nova relação de família. No entanto, observa-se uma grande lacuna legislativa especificamente no que concerne aos direitos dos casais homoafetivos com filhos, como, por exemplo, a possibilidade de registro duplo - pai e pai, mãe e mãe.

Sendo assim, diante da falta de regulação legal acerca do tema, cabe ao Poder Judiciário, ao se deparar com um caso concreto, solucionar os conflitos, utilizando-se dos princípios gerais de direito, equidade e analogia.

\section{REFERÊNCIAS}

AMIM, Andréa Rodrigues. O novo código civil: do direito de família. Rio de Janeiro: Freitas Bastos, 2002.

BARBOSA, Heloisa Helena. Procedimentos para redesignação sexual: um processo biologicamente inadequado. 2010. Tese (Doutorado em Ciências na Área de Saúde Pública) - Escola Nacional de Saúde Pública Sergio Arouca, Rio de Janeiro, 2010.

BOBBIO, Norberto. A era dos direitos. Rio de Janeiro: Campus, 1992.

BRASIL. Constituição (1988). Constituição da República Federativa do Brasil. Disponível em:<http://www.planalto.gov.br/ccivil_03/ constituicao/constituicao.htm>. Acesso em: 1 mar. 2013.

BRASIL. Lei $n^{\circ}$ 9263, de 12 de janeiro de 1996. Regula o $\S 7^{\circ}$ do art. 226 da Constituição Federal, que trata do planejamento familiar, estabelece penalidades e dá outras providências. Diário Oficial da União, Brasília, 15 jan. 1996. Disponível em: <http://www.planalto.gov.br/ ccivil_03/1eis/19263.htm>. Acesso em: 1 mar. 2013.

BRASIL. Lei $n^{\circ}$ 9278, de 10 de maio de 1996. Regula o $\S 3^{\circ}$ do art. 226 da Constituição Federal. Diário Oficial da União, Brasília, 13 maio 1996. Disponível em: < http://www.planalto.gov.br/ccivil_03/leis/ 19278.htm>. Acesso em: 1 mar. 2013. 
BRASIL. Lei $\mathrm{n}^{\circ} 10.406$, de 10 de janeiro de 2002. Institui o Código Civil. Diário Oficial da União, Brasília, 11 jan. 2002. Disponível em: $<$ http:// www.planalto.gov.br/ccivil_03/leis/2002/L10406compilada.htm>. Acesso em: 1 mar. 2013.

BRASIL. Lei $\mathrm{n}^{\circ} 11.340$, de 7 de agosto de 2006. Cria mecanismos para coibir a violência doméstica e familiar contra a mulher, nos termos do $\S 8^{\circ}$ do art. 226 da Constituição Federal, da Convenção sobre a Eliminação de Todas as Formas de Discriminação contra as Mulheres e da Convenção Interamericana para Prevenir, Punir e Erradicar a Violência contra a Mulher [...]. Diário Oficial da União, Brasília, 8 ago. 2006. Disponível em:<http://www.planalto.gov.br/ ccivil_03/_ato2004-2006/2006/lei/ 111340.htm>. Acesso em 01 mar 2013.

CALMON, Guilherme Nogueira. Direito de família brasileiro. São Paulo: Juarez de Oliveira, 2001.

CONSELHO FEDERAL DE MEDICINA. A Resolução CFM n ${ }^{\circ} 1.358$ / 92, após 18 anos de vigência, recebeu modificações relativas à reprodução assistida, o que gerou a presente resolução, que a substitui in totum. Resolução n. 1.957, de 15 de dezembro de 2010. Diário Oficial da União, Brasília, 6 jan. 2011. Disponível em: <http://

www.portalmedico.org.br/resolucoes/CFM/2010/1957_2010.htm>. Acesso em: 1 mar. 2013.

CONSELHO FEDERAL DE MEDICINA. Resolução n. 1.358, de 19 de novembro de 1992. Adota normas éticas para utilização das técnicas de reprodução assistida. Diário Oficial da União, Brasília, 19 nov. 1992. Disponível em: <http://www.portalmedico.org.br/resolucoes/CFM/1992/ 1358_1992.htm>. Acesso em: 1 mar. 2013.

DIAS. Maria Berenice. Manual de direito das famílias. 8. ed. rev. atual. e ampl. São Paulo: Revista dos Tribunais, 2011.

DINIZ, Maria Helena. O estado atual do biodireito. São Paulo: Saraiva, 2002. 
FACHIN, Luis Edson. Direito de família: elementos críticos à luz do novo código civil brasileiro. 2. ed. rev e atual. Rio de Janeiro: Renovar, 2003.

GOMES, Orlando. Contratos. Rio de Janeiro: Ed. Forense, 1999.

GROENINGA, Giselle Câmara. Família: um caleidoscópio de relações. In: PEREIRA, Rodrigo da Cunha (Coord.). Direito de Família e Psicanálise. São Paulo: Imago, 2003.

HIRONAKA, Giselda. Direito civil: estudos. Belo Horizonte: Del Rey, 2000 .

LEITE, Eduardo de Oliveira. Procriações e o direito: aspectos médicos, religiosos, psicológicos, éticos e jurídicos. São Paulo: Revista dos Tribunais, 1995.

LÓPEZ, Mário. Fundamentos da clínica médica: a relação pacientemédico. Rio de Janeiro: Médsin Ed. Médica e Científica, 1997.

MEIRELLES, Jussara. Filhos da reprodução assistida. In: PEREIRA, Rodrigo da Cunha (coord.). Anais do III Congresso Brasileiro de Direito de Família. Família e Cidadania. O novo CCB e a vacatio legis. Belo Horizonte: Del Rey, 2002.

NADER, Paulo. Curso de direito civil: direito de família. Rio de Janeiro: Forense, 2006. v.5.

PEREIRA, Caio Mário da Silva. Instituições de direito civil: direito de família. 16. ed. Rio de Janeiro: Forense, 2007. v.5.

SAUWEN, Regina Fiúza; HRYNIEWICZ, Severo. O direito in vitro, da bioética ao biodireito. Rio de Janeiro: Ed. Lúmen Juris, 2000.

SILVA, Ivan de Oliveira. Biodireito, bioética e patrimônio genético brasileiro. São Paulo: Pillares, 2008. 
VASCONCELOS, Cristiane Beuren. A proteção jurídica do ser humano in vitro na era da biotecnologia. São Paulo: Atlas, 2006.

VILLELA, João Baptista. Desbiologização da paternidade. Revista da Faculdade de Direito da Universidade Federal de Minas Gerais, Belo Horizonte, n. 21, maio, 1999.

Recebido em: 2013-08-08 Aprovado para publicação em: 2013-08-16

Como citar: FERRARI, Geala Geslaine; FRANÇA, Loreanne Manuella de Castro. As novas formas de entidades familiares advindas com a Constituição Federal de 1988 e a reprodução humana assistida como instrumento facilitador para a formação das famílias homoafetivas. Direito Público, Londrina, v.8, n.2, p., mai/ago.2013. DOI: 10.5433/1980511X.2013v8n2p 